\title{
A Rare Abdominal Tumor in a Pediatric Age Group: Pheochromocytoma
}

\author{
Rajesh Prasad Sah ${ }^{1 *}$, Sah RG² and Shaukat Mahmood ${ }^{3}$ \\ ${ }^{1}$ Department of Pediatric Surgery, Kanti Children Hospital, Maharajgunj, Kathmandu, Nepal \\ ${ }^{2}$ Department of Clinical Neurosciences, University of Calgary, Canada \\ ${ }^{3}$ Department of Pediatric Surgery, King Edward Medical University, Mayo Hospital, Lahore, Pakistan
}

*Corresponding author: Rajesh Prasad Sah, Department of Pediatric surgery, Kanti Children Hospital, Maharajgunj, Kathmandu, Nepal, Phone: +9977-9841649300, Fax: +977- 523686; E-mail: drrajeshsah@gmail.com

Rec Date: July 31, 2017, Acc Date: August 12, 2017, Pub Date: August 14, 2017

Citation: Sah PR, Sah RG, Mahmood S (2017) A Rare Abdominal Tumor in a Pediatric Age Group: Pheochromocytoma. Med Case Rep, 2017, Vol. 3 No.4: 37.

\section{Abstract}

We report a case of 10 year old boy with unilateral pheochromocytoma who presented with short history of abdominal pain and palpitation. He remained under treatment by general practitioners and incidentally markedly high blood pressure was noted. Ultrasound and abdominal CT oriented towards the diagnosis. After careful preparation and preoperative optimization, surgical excision (right total adrenalectomy) was done and an unusual large pheochromocytoma tumor of about $8 \times$ $10 \mathrm{~cm}$ adherent to liver and IVC was excised and histopathological confirmed without any evidence of malignancy.

\section{Keywords: $\quad$ Adrenalectomy; Laparotomy;} Pheochromocytoma

\section{Introduction}

Pheochromocytoma is a rare tumor of endocrine origin and a cause of secondary hypertension in children [1]. It is a catecholamine secreting tumor that arises from chromaffin cells of the sympathetic nervous system. The incidence is 1 in 500000 live births. The diagnosis benefited from the advancement of imaging, including Computed Tomography (CT), Magnetic Resonance Imaging (MRI) and metaiodobenzylguanidine scintigraphy (MIBG). Its therapeutic management is multidisciplinary. Confirmatory diagnosis is based on the histopathological study of the surgical specimen. We report the case of a 10 -year-old boy with a unilatera pheochromocytoma revealed by short history abdominal pain and palpitation that has evolved well after surgical treatment.

\section{Case Presentation}

A 10-year-old boy with two month's history of abdominal pain, which was central (peri-umbilical), episodic and severe in intensity but non-radiating, he reported in our pediatric OPD. The pain increased with meals and was not associated with nausea and vomiting. He also had reduced weight of about 6 $\mathrm{kg}$. Before coming to our department, the patient was taken to the local doctor where medication was prescribed. Pain was relieved for few days, however, after 2-3 days; he started having abdominal pain again with off/on palpitation which was not relieved by the medication. So, the patient was brought to the Pediatric Medicine OPD, Mayo Hospital.

The patient was admitted for 9 days. He was investigated for abdominal pain and palpitation. During his stay, the patient's BP (blood pressure) recorded was up to $160 / 100 \mathrm{mmHg}$, which was controlled with medication. Urinary VMA (vanillymandelic acid) was $18.0 \mathrm{mg} / 24 \mathrm{hr}$. Ultrasonography showed a solid well capsulated solid lesion measuring $3.9 \times 4.0 \mathrm{~cm}$ in the area of right adrenal gland displacing inferior vena cava (IVC). An abdominal CT scan was obtained which revealed a heterogeneous mixed density lesion measuring about $4 \mathrm{~cm}$ in size with solid and cystic components with enhancement both in arterial and venous phases. The lesion was found adjacent to segment $\mathrm{VI}$ of the liver and was separable from it. The mass displaces the IVC. Right adrenal gland was not visualized separate from the mass; hence the mass was diagnosed to be arising from the right adrenal gland (Figure 1). The left adrenal gland was normal.

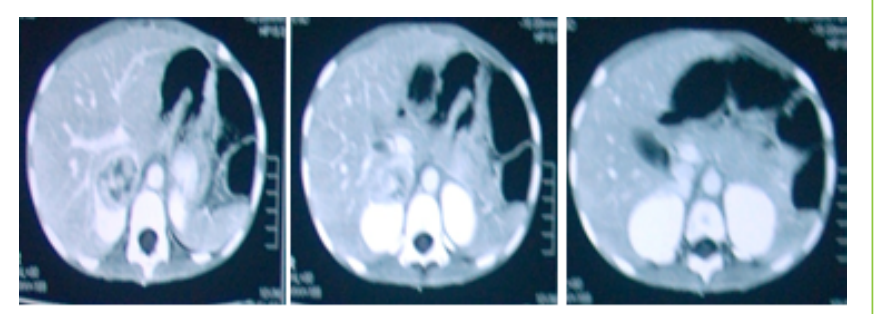

Figure 1 The representative axial images of contrast enchanced CT scan showing mass in the right adrenal gland pushing IVC upward.

He was treated with alpha receptor blocking drugs prior to surgery. After pre-operative optimization, surgery was done and an unusually large tumor of about $8 \times 10 \mathrm{~cm}$ adherent to liver and IVC was excised (Figure 2). 


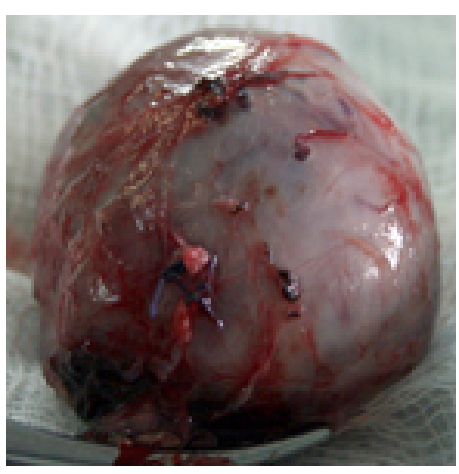

Figure 2 Shows an excised tumor (pheochromocytoma) of size $8 \times 10 \mathrm{~cm}$ after laparotomy in a ten year child.

Histopathology confirmed the diagnosis of Pheochromocytoma without any evidence of malignancy. He made an uneventful recovery with normalization of blood pressure and was discharged after 10th day of surgery. BP readings were normal on follow up on many occasions.

\section{Discussion}

Pheochromocytoma is a neuroendocrine tumor derived from the chromaffin cells of the sympathetic nervous system $[2,3]$. It originates in the adrenal gland, but can arise in any part of the body that contains chromaffin cells [4]. In children, pheochromocytoma is more frequently familial, extra-adrenal, bilateral and multifocal than in adults [5]. Patients having pheochromocytoma may present not only with classical signs and symptoms, but also with various non-specific symptoms including abdominal pain $[6,7]$. Takeda et al. reported in their case that non- specific abdominal pain was most probably due to hypercalcemia, but in our case report the patient had a short history of abdominal pain which was probably due to the tumor itself and not due to increased calcium level [8]. Presence of hypertension in children is uncommon and secondary to underlying pathology. Our patient's BP was not recorded during his initial visit to the general practitioner and was blindly treated for abdominal pain. BP measurement is not a routine check-up in pediatric age group. However, during pediatric assessment BP measurement should be considered an essential component [9]. Elevated levels of catecholamine in blood and urine examination are useful in diagnosing pheochromocytoma. Radical excision is the best treatment of adrenal pheochromocytoma [10]. Minimal handling of the tumor and early venous control are the best safeguards against intraoperative hypertensive crises. The blood pressure may not return to normal immediately in long standing cases and may require medication for some time.

\section{Conclusion}

The overall prognosis in patient with pheochromocytoma appears to be related to tumor size, degree of uncontrolled $\mathrm{HTN}$, and the presence of metastatic disease.

\section{References}

1. Silverman MA, Walker AR, Nicolau DD, Bono MJ (2000) The frequency of blood pressure measurements in children in four EDs. Am J Emerg Med 18: 784-788.

2. Yasukawa M, Kido T (2008) Pheochromocytoma of the posterior mediastinum undiagnosed until the onset of intraoperative hypertension. Gen Thorac Cardiovasc Surg 56: 509-511.

3. Young WF Jr (2006) Paragangliomas: clinical overview. Ann N Y Acad Sci 1073: 21-29.

4. Ross J (2000) Pheochromocytoma. Special considerations in children. Urol Clin North Am 27: 393-402.

5. Havekes B, Romijn JA, Eisenhofer G, Adams K, Pacak K (2009) Update on pediatric pheochromocytoma. Pediatr. Nephrol 24: 943-950.

6. Kopetschke R, Slisko M, Kilisli A, Tuschy U, Wallaschofski $H$, et al. (2009) Frequent incidental discovery of phaeochromocytoma: data from a German cohort of 201 phaeochromocytoma. Eur J Endocrinol 161: 355-361.

7. Neumann HP, Eng C (2009) The approach to the patient with paraganglioma. J Clin Endocrinol Metab 94: 2677-2683.

8. Takeda K, Hara N, Kawaguchi M, Nishiyama T, Takahashi K (2010) Parathyroid hormone-related peptide-producing non-familial pheochromocytoma in a child. IJU 10: 1442-2042.

9. National High Blood Pressure Education Program Working Group on High Blood Pressure in Children and Adolescents (2004) The fourth report on the diagnosis, evaluation and treatment of high blood pressure in children and adolescents. Pediatrics 114: 555-576.

10. Bissada N, Safwat A, Seyam R, Al-Sobhi S, Hanash K, et al. (2008) Pheochromocytoma in children and adolescents: A clinical spectrum. J Pediatr Surg 43:540-543. 